\title{
Crown Lengthening as Treatment for Altered Passive Eruption: Review and Case Report
}

\author{
${ }^{1}$ Shelon Cristina Souza Pinto, ${ }^{2}$ Cristian Higashi, ${ }^{3}$ Elize Bonafé, ${ }^{4}$ Gibson Luiz Pilatti, ${ }^{5}$ Fábio André Santos \\ ${ }^{6}$ Mateus Rodrigues Tonetto, ${ }^{7}$ Suellen Nogueira Linares Lima, ${ }^{8}$ Matheus Coelho Bandéca
}

\begin{abstract}
This case report relates a patient with altered passive eruption (APE) treated with surgical crown lengthening. There is a strong association between smile esthetics and periodontal tissues. 'Gummy smile' constitutes a relatively frequent esthetic disadvantage characterized by excessive display of the gums during upper lip smiling. One situation that can lead to gummy smile is APE. There are many important diagnostic factors connected with APE. These include making a correct diagnosis; considering facial and oral features before considering the most appropriate periodontal treatment. A 21-year-old female patient presented to the dental clinic expressing to be discontent with her smile, due to the display of gingiva when she smiles. Before choosing the adequate treatment, esthetics and periodontal factors were analyzed. In the present case report, surgical crown lengthening was the treatment chosen. Through a correct diagnosis and technique, it was possible to obtain harmony in the smile. Crown-lengthening surgery is an important choice of treatment, because it is a less invasive technique and it permits the establishment of an esthetical smile.
\end{abstract}

Keywords: Altered passive eruption, Crown lengthening, Gummy smile, Treatment.

How to cite this article: Pinto SCS, Higashi C, Bonafé E, Pilatti GL, Santos FA, Tonetto MR, Lima SNL, Bandéca MC. Crown Lengthening as Treatment for Altered Passive Eruption: Review and Case Report. World J Dent 2015;6(3):178-183.

Source of support: Nil

Conflict of interest: None

\section{INTRODUCTION}

The periodontal tissues are considered to be an important factor when trying to achieve esthetic smiles. ${ }^{1}$ The evolution of periodontal plastic surgical techniques and better understanding of the features associated with an esthetic smile have permitted the existence of various therapeutic

\footnotetext{
${ }^{1,4-6}$ Professor, ${ }^{2,3} \mathrm{PhD}$ Student, ${ }^{7} \mathrm{MSc}$ Student, ${ }^{8} \mathrm{Head}$

${ }^{1-5}$ Department of Dentistry, Ponta Grossa State University, Ponta Grossa, Brazil

${ }^{6}$ Department of Postgraduate Program in Integrated Dental Sciences, University of Cuiaba, Cuiabá, Brazil

${ }^{7,8}$ Department of Postgraduate Program in Dentistry, CEUMA University, Sao Luis, Brazil

Corresponding Author: Matheus Coelho Bandéca, Head Department of Postgraduate Program in Dentistry, CEUMA University, Sao Luis, Brazil, e-mail: mbandeca@gmail.com
}

procedures in periodontology. This has contributed to a more multidisciplinary approach in dentistry treatment. To achieve excellent periodontal esthetics, it requires a treatment planning with the evaluation of all factors that interfere with the harmony and symmetry of the smile elements. ${ }^{2,3}$

A smile is considered beautiful, attractive and healthy when it has an equilibrium between shape and symmetry of teeth, lips and gingiva. Not to mention the relation and harmony in the face. ${ }^{2-4}$ The observation of kindness shown in the smile is fundamental in the esthetic planning, since gingiva widely exposed, exalts features that diminish the look, that of a beautiful smile.

There are three kinds of smile: high, medium and low. The high smile is considered normal when presented with exposed gingiva of 1 to $3 \mathrm{~mm}$. If the exposure presents more than $3 \mathrm{~mm}$, the gummy smile is characterized. ${ }^{5,6}$ The medium smile is known to be more attractive and it is characterized by presence of tooth, interdental gingiva and the edge of free gingiva around the cervical portion of the teeth, and is completely exposed. ${ }^{4}$

The shorter the superior lip, the higher the smile line. This condition favors the exposure of gingiva, leading to a gummy smile, going against the fundamentals of esthetic resolution. ${ }^{7}$

\section{CONCEPT AND CLASSIFICATION OF APE}

Altered passive eruption (APE) is characterized by excessive gingiva in relation to the crown of the tooth. This condition can be localized or generalized and should be considered when planning restorative, orthodontic and esthetical treatment. The term 'APE' refers to the supposed causal mechanism underlying the tooth eruption. ${ }^{8}$

Tooth eruption presents an active and passive phase. Active eruption is the movement of the teeth in the direction of the occlusal plane, while passive eruption is related to the exposure of the teeth by apical migration of the gingiva. Sometimes, passive eruption can be considered a pathologic process, involving a more coronal periodontium, and it has been referred to as APE/delayed passive eruption. ${ }^{8,9}$

Coslet et al classified APE into two distinct types (Flow Chart 1): 
- Type I: Excessive amount of gingiva measured from the free gingival margin to the mucogingival junction

- Type II: Measurement from the free gingival margin to the mucogingival junction shows a normal dimension of gingiva.

Altered passive eruption can be further subdivided on subcategories $\mathrm{A}$ and $\mathrm{B}$, considering the relationship of the osseous crest to the cementoenamel junction (CEJ) of the tooth (Flow Chart 1). The subclassification A shows a dimension between the level of CEJ and osseous crest greater than $1 \mathrm{~mm}$, it is a sufficient area to insert the connective tissue fibrous attachment component of the biological width. In the subclassification $\mathrm{B}$, the osseous crest is close to CEJ, decreasing the space for the insertion of connective tissue of the biological width. ${ }^{4,10}$

\section{DIAGNOSING APE}

To analyze a 'gummy smile', clinical examination is required. This begins with extraoral conditions: height and facial symmetry, face height, length and thickness of the lip, profile and smile line, followed by the evaluation of intraoral conditions: teeth dimensions, height of the anatomic crowns vs height of the clinical crowns, thickness, width, positions and contour of gingival tissue. ${ }^{3,11}$

The main aspects related to a gummy smile are: excessive vertical growth, tooth extrusion, short upper lip, APE and the combination of various other factors. ${ }^{4,6}$

Clinically, the most common sign of APE is a short tooth crown. Besides the excess gingiva covering the tooth crown, other aspects must be considered in the APE diagnosis. ${ }^{4,8,9}$

Normally, in cases of APE no other clinical signs of disease may be found, such as, bleeding upon probing, suppuration, inflammation or radiographic bone loss. The normal position of $\mathrm{CEJ}$ is apical to the gingival margin of

Flow Chart 1: Classification and subclassification of APE (GM: Gingival margin; MGJ: Mucogingival junction; CEJ: Cementoenamel junction)

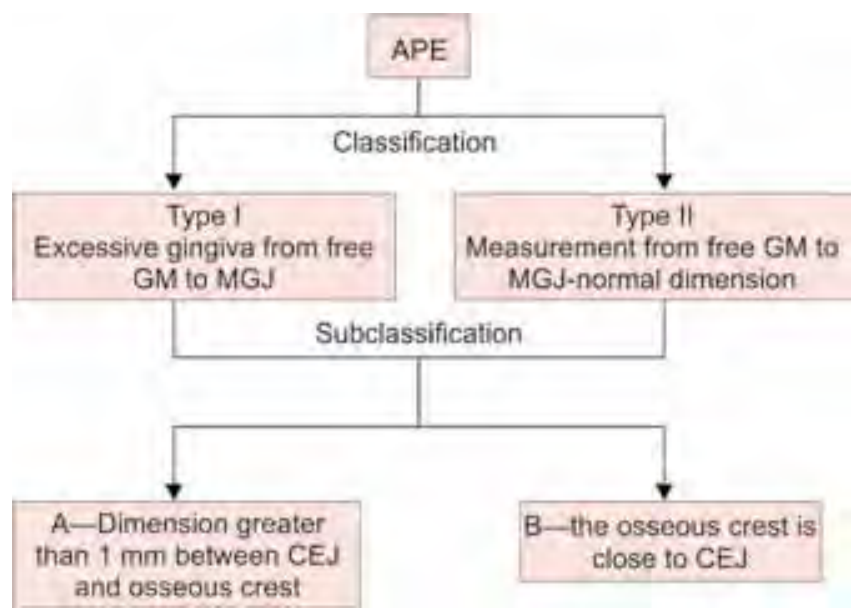

the anatomic crown, however, the sulcus depth usually measures 1 to $3 \mathrm{~mm}$. In a presence of APE, the CEJ may be up to $10 \mathrm{~mm}$ apical to the gingival margin. ${ }^{9}$

Specification of the age is also an important factor in the diagnosis. During childhood and puberty, excess gingiva covering the teeth is a normal condition, because eruption has not yet been completed. The eruption of anterior teeth finishes in the end of adolescence, considering posterior teeth, the eruption finishes in the third decade of life. ${ }^{8}$

During the APE, diagnosis is important to consider the classification and subclassification of this condition, because the diagnosis between the two types is important to determine the ideal treatment. In order to establish type I or II, it is necessary to observe the amount of keratinized gingiva. Considering the subclassification, subcategory A or B is detected by the process of bone sounding via sulcus. ${ }^{4}$

\section{ETIOLOGY AND TREATMENT OF 'GUMMY SMILE'}

There are some extraoral causes of a gummy smile, which are vertical maxillary excess, a hypermobile/short upper lip. When there are significant discrepancies among one or more extraoral parameters, it is unlikely to expect that only intraoral proceedings can promote a suitable result. In these cases, orthognathic or plastic surgery must be considered. ${ }^{1,11}$

In cases of vertical maxillary excess, the orthognathic surgery alone is considered the option of treatment. Hypermobility of the upper lip is due to hyperfunction of the lip elevator muscles and can often result in excessive displays of gingiva. Recently, the injection of botulinum toxin type A has been suggested for treatment of hypermobility of the upper lip, but this may only provide temporary benefits. ${ }^{12}$ When vertical maxillary excess is associated with hypermobility of the upper lip, a recent minimally invasive surgical procedure was suggested. The mucosal coronally positioned flap procedure aims to reduce displays of the gingiva by shortening the vestibular depth. ${ }^{1}$ This treatment can be performed by the periodontist.

The specified indication for the periodontist to perform a treatment in cases of a gummy smile is the APE. ${ }^{4}$ This diagnosis is confirmed when the facial proportion and labial length/mobility are normal. Therefore, there is exposed gingiva and a short clinic crown. ${ }^{1,4}$

\section{TREATMENT PLANNING FOR APE}

Crown lengthening via periodontal surgery is the treatment of choice in cases where there are excessive displays 
of gingiva, as a result of APE. The surgical technique selected for crown lengthening procedures must provide the clinician access to the crestal bone. And as a function of that, the periodontal flap is the technique of choice. The gingivectomy does not allow access to the alveolar bone. Therefore, the gingivectomy technique is contraindicated for treatment of the majority of APE cases. ${ }^{1,12}$

Gingivectomy can be considered a treatment choice in APE cases classified as type I and subclassified as A4, however, in the most cases is not possible to be sure if the dimension between the level of CEJ and osseous crest is greater than $1 \mathrm{~mm}$ the osseous crest.

This case report relates a patient with APE treated with surgical crown lengthening.

\section{CASE REPORT}

A 21-year-old female patient presented to the dental clinic at Ponta Grossa State University and expressed discontent with her smile, due to the display of gingiva when she smiles (Fig. 1).

The first esthetic factor analyzed was the proportionality among the teeth, which depends on the relation between length and width of the teeth and the arrangement and shape in the arch. ${ }^{14,15}$

The initial examination verified the presence of short teeth in relation to the gingival margin, absence of inflammation and growth of the gingiva. In order to evaluate the periodontal condition, probing depth, periodontal attachment loss, gingival bleeding and suppuration examinations were performed. The periodontal examination verified the presence of healthy periodontal tissue.

After evaluation of periodontal and esthetic aspects, the diagnosis of APE was established.

During an interview with the patient, it was noted that her posed smile did not display as much gingiva

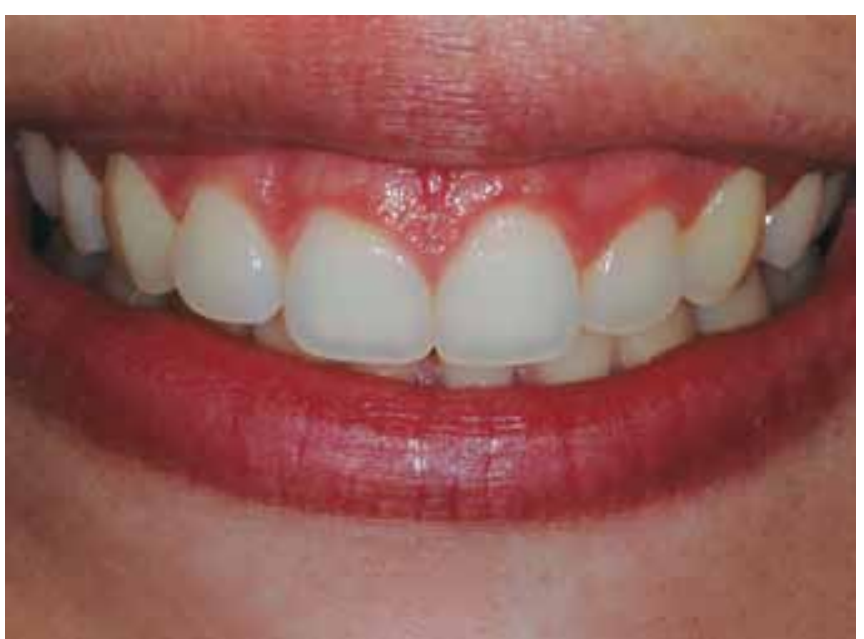

Fig. 1: Baseline clinical aspect as her dynamic smile, which was noticeably wider. The patient showed a great amount of inserted gingiva, permitting the performance of the crown lengthening as a preference of treatment. The amount of inserted gingiva also permitted the confection of total flap with internal-beveled and removal of a gingival collar (Fig. 1). Considering the amount keratinized gingiva, the present case report was classified as type I, and after the evaluating through bone sounding via sulcus, the condition was subclassified as A. ${ }^{4,6,9,10}$

The surgery procedure was performed in the following sequence:

- Infiltrative anesthesia

- Incision using a No. 15 blade (MedGoldman ${ }^{\mathrm{TM}}$, São Paulo, Brazil): internal-bevel incision (Fig. 2A)

- Secondary intrasulcular incision (Fig. 2B)

- Removal of gingival collar (Fig. 2C)

- Full-thickness mucogingival flap reflection

- Removal of gingival collar and root instrumentation (Fig. 2D), followed by positioning and suture of the soft tissue flaps (Fig. 3A).

In this case, it was not necessary to perform osteotomy (APE subclassified as A). After 11 days, the suture was removed and appeared to have satisfactory healing (Fig. 3B). After 90 days, on a follow-up visit, a harmonic appearance of gingival tissue was showed, except a persisting papillary inflammation (Fig. 4). During this period the patient was under treatment for an ovarian cyst, which required a hormonal regulation treatment. Hormone therapy was probably responsible for the transient gingival inflammation.

After 3 years of the postoperative period, total healing was observed and the patient was satisfied with the final result (Fig. 5).

\section{DISCUSSION}

In establishing the smiles esthetic factors, shape, color and arrangement of anterior teeth must be considered in the harmony shown in the face of the patient. In order to have an ideal choice of treatment, the important aspects to be evaluated by the periodontist are as follows:

- Periodontal condition

- Periodontal biotope

- Smile line and gingival exposition

- Gingival outline and Zenith

- Interdental papilla

- Gingival recession

- Gingival color. ${ }^{13,5}$

After evaluating the presence of 'gummy smile', the tooth smile components can be analyzed. Usually, maxillary central incisors have a width-to-length ratio 

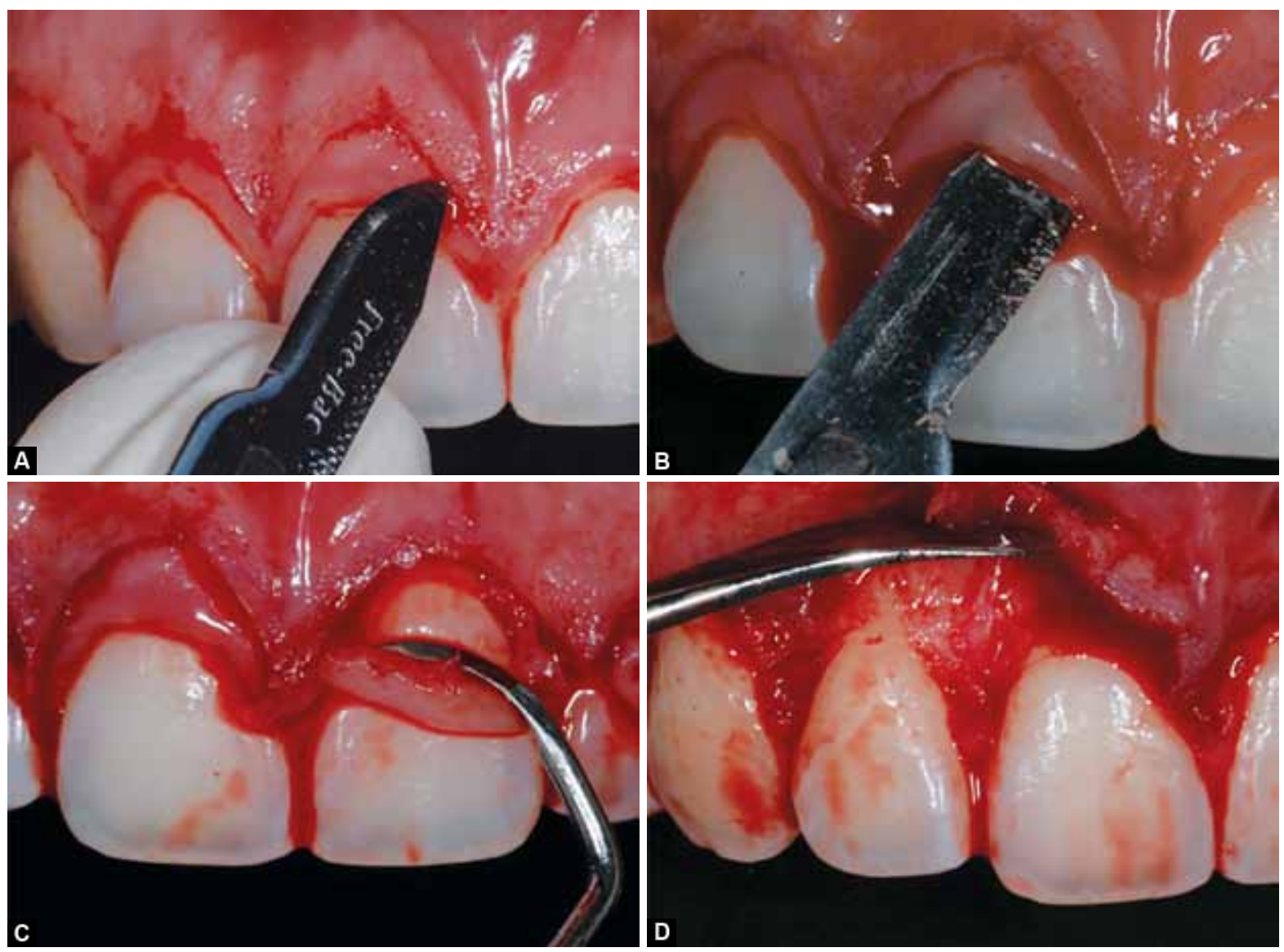

Figs 2A to D: (A) Parabolic incision: internal-bevel incision, (B) secondary intrasulcular incision, (C) removal of gingival collar and (D) full-thickness mucogingival flap reflection
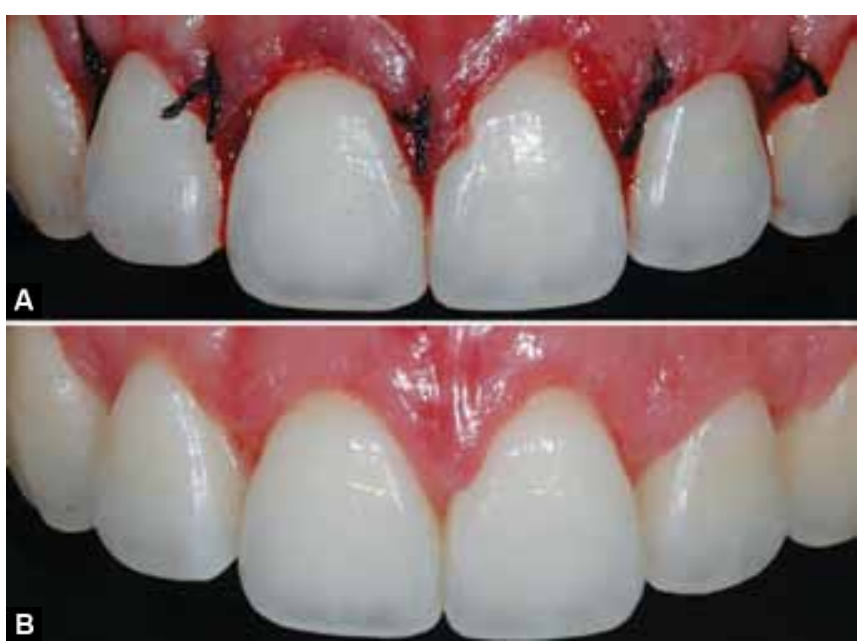

Figs 3A and B: $(A)$ The final suture is a single suture connecting the surgical papilla to the anatomic papilla and (B) at time of suture removal (11 days), the harmony of mucogingival tissue is re-established

of 0.75 to $0.80 .^{4}$ The gingival margin of the maxillary lateral incisor is normally $1.0 \mathrm{~mm}$ below that of the adjacent maxillary central incisors/canines. An ideal smile design also depends on the dental midline of the maxillary and mandibular arch, besides the correct posterior tooth length. ${ }^{1,16-18}$ Another factor to consider is to avoid the loss of interdental papilla, as it will detract from final smile esthetics. The biology of periodontal tissues needs to be respected for a complete success in therapy surgery. ${ }^{11,17-19}$

In cases of $\mathrm{APE}$, the modalities of treatment are directly related to a causal agent. Techniques, such as conventional gingivectomy (external-beveled) and flap (internal-beveled) with removal of bone tissue have been proposed for treatment of 'gummy smile', caused by alteration of passive eruption and dentoalveolar extrusion..$^{11,15}$ However, the gingivectomy technique, because of not allowing access to the alveolar bone, is contraindicated for treatment of the majority of cases that present APE. ${ }^{13}$

In the present case, the appropriate treatment was crown lengthening, with mucoperiosteal flap through internal-beveled, due to the large amount of keratinized gingiva, permitting further lengthening of up to 3 to $4 \mathrm{~mm}$ after incision. However, if the amount of initial keratinized gingiva is not enough, the performance of apical position flat is indicated. When the bone crest is less than $3 \mathrm{~mm}$ distant from the CEJ, regardless of the amount keratinized gingiva, it is necessary to perform osteoplasty and osteotomy, creating the necessary biological width $(3 \mathrm{~mm}) .{ }^{7,11,15}$ 


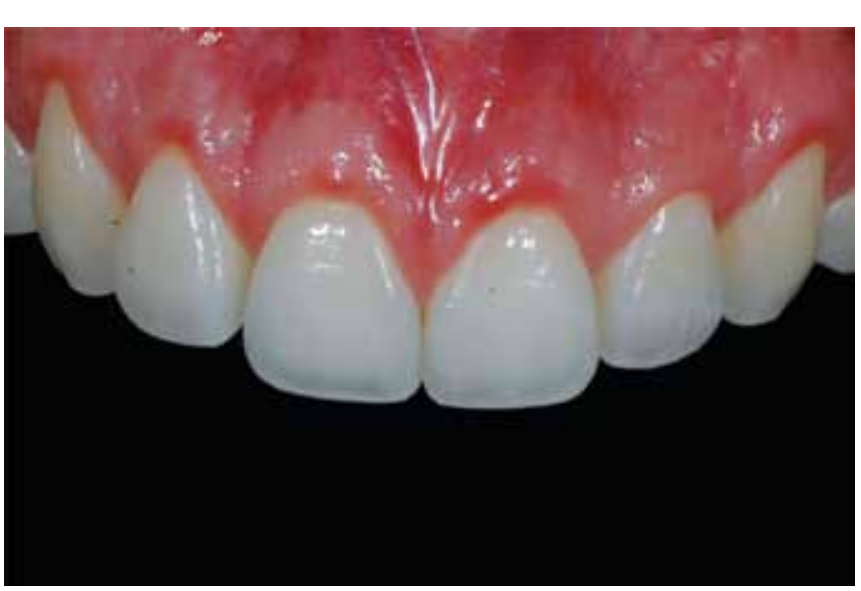

Fig. 4: After 90 days, on a follow-up visit, a harmonic appearance of gingival tissue

More invasive techniques can be used to treat APE, such as orthognathic surgery and plastic surgery. ${ }^{1,3,11}$ Invasive techniques for treating APE are considered in cases involving extraoral causes of a gummy smile, such as vertical maxillary excess and hypermobile/short upper lip. It is unlikely to expect that intraoral proceedings can promote a suitable result in the treatment of APE when the cause is related to high discrepancies among extraoral parameters. ${ }^{111,13}$

The patient showed APE classified as type I, because she had an increase of gingiva when the free gingiva to mucogingival junction was measured. Her condition was subclassified as subgroup A, therefore the bone crest was distant to the CEJ. This provides enough space for insertion of gingival fiber. Through probing we were able to detect whether the bone crest was in the same level of CEJ. ${ }^{11}$

The clinical crown is the portion of the tooth that extends occlusally or incisally from the investing soft tissue, usually the gingival. ${ }^{20-22}$ Esthetic deficiency is one indication to perform this treatment, as APE, permitting additional lengthening of the teeth when is required. This improves tooth proportion and symmetry and/or decreases the 'gingival' appearance of a smile. 1,21,22 $^{1,2}$

\section{CONCLUSION}

Through a correct diagnosis and technique, it was possible to obtain harmony in the smile. Crown-lengthening surgery is an important choice of treatment, because it is a less invasive technique ${ }^{13}$ and it permits the establishment of an esthetical smile.

\section{CLINICAL RELEVANCE}

The biology of periodontal tissues and facial features must be identified before performing any surgery procedure. Then, the right diagnosis will be reached, which permits to choose the best treatment for that case. It is

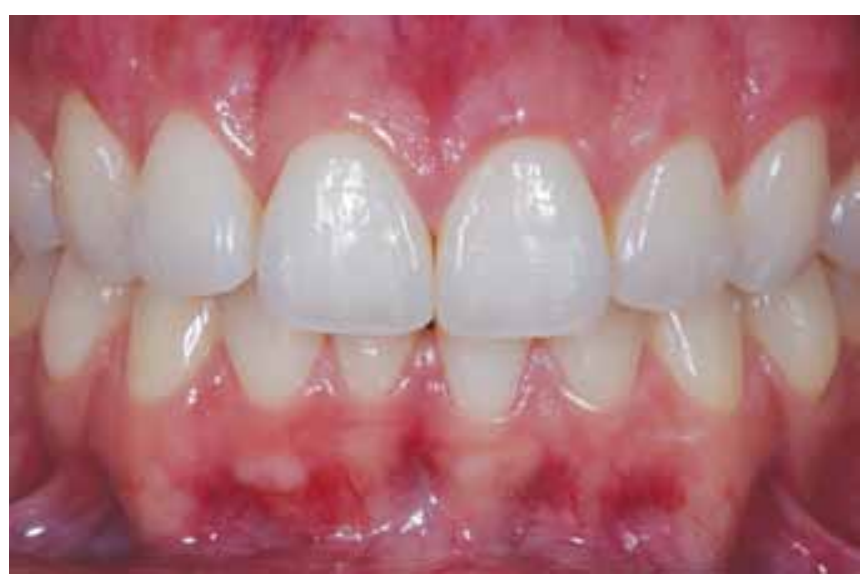

Fig. 5: Three years follow-up clinical aspect. The gummy smile is completely solved, good gingival health and form are achieved

extremely important for the clinical practice to approach APE case reports.

\section{REFERENCES}

1. Humayun N, Kolhatkar S, Souiyas J, Bhola M. Mucosal coronally positioned flap (MCPF) for the management of excessive gingival display in the presence of hypermobility of the upper lip and vertical maxillary excess: a case report. J Periodontol 2010 Dec;81(12):1858-1863.

2. Mummidi B, Rao CH, Prasanna AL, Vijay M, Reddy KV, Raju MA. Esthetic dentistry in patients with bilaterally missing maxillary lateral incisors: a multidisciplinary case report. J Contemp Dent Pract 2013 Mar 1;14(2):348-354.

3. Biniraj KR, Janardhanan M, Sunil MM, Sagir M, Hariprasad A, Paul TP, Emmatty R. A combined periodontal-prosthetic treatment approach to manage unusual gingival visibility in resting lip position and inversely inclined upper anterior teeth: a case report with discussion. J Int Oral Health 2015 Mar;7(3):64-67.

4. Silberg N, Goldstein M, Smidt A. Excessive gingival displayetiology, diagnosis and treatment modalities. Quintessence Int 2009 Nov-Dec;40(10):809-818.

5. Blitz N. Criteria for success in creating beautiful smiles. Oral Health 1997 Dec;87(12):38-42.

6. Levine RA, Mcguire M. The diagnosis and treatment of the gummy smile. Compend Contin Educ Dent 1997 Aug;18(8): 757-762.

7. Dolt AH, Robbins JW. Altered passive eruption: an etiology of short clinical crowns. Quintessence Int 1997 Jun;28(6): 363-372.

8. Alpiste-Illueca F. Altered passive eruption: a little-known clinical situation. Med Oral Patol Oral Cir Buccal 2011 Jan 1; 16(1):e100-104.

9. Nart J, Carrió N, Valles C, Solís-Moreno C, Nart M, Reñé R, Esquinas C, Puigdollers A. Prevalence of altered passive eruption in orthodontically treated and untreated patients. J Periodontol 2014 Nov;85(11):e348-353.

10. Coslet GJ, Vanarsdall R, Weisgold A. Diagnosis and classification of delayed passive eruption of the dentogingival junction in the adult. Alpha Omegan 1977 Dec;70(3):24-28.

11. Rossi R, Brunelli G, Piras V, Pilloni A. Altered passive eruption and familial trait: a preliminary investigation. Int J Dent 2014;2014:874092. 
12. Polo M. Botulinum toxin type A (Botox) for the neuromuscular correction of excessive gingival display on smiling (gummy smile). Am J Orthod Dentofacial Orthop 2008 Feb;133(2):195-203.

13. Camargo PM, Melnick PR, Camargo LM. Clinical crown lengthening in the esthetic zone. J Calif Dent Assoc 2007 Jul; 35(7):487-498.

14. Castillo R. The problem of Insufficient incisal display: a case presentation. Eur J Esthet Dent 2010 Summer;5(2):140-156.

15. Lanning SK, Waldrop TC, Gunsolley JC, Maynard G. Surgical crown lengthening: evaluation of the biological width. J Periodontol 2003 Apr;74(4):468-474.

16. Guo J, Gong H, Tian W, Bai D. Alteration of gingival exposure and its aesthetic effect. J Craniofac Surg 2011 May;22(3):909-913.

17. Padbury A Jr, Eber R, Wang HL. Interactions between the gingiva and the margin of restorations. J Clin Periodontol 2003 May;30(5):379-385.
18. Abdullah WA, Khalil HS, Alhindi MM, Marzook H. Modifying gummy smile: a minimally invasive approach. J Contemp Dent Pract 2014 Nov 1;15(6):821-826.

19. Tarnow DP, Magner AW, Fletcher P. The effect of the distance from the contact point to the crest of bone on the presence or absence of the interproximal dental papilla. J Periodontol 1992 Dec;63(12):995-996.

20. Roshna T, Nandakumar K. Anterior esthetic gingival depigmentation and crown lengthening: report of a case. J Contemp Dent Pract 2005 Aug 15;6(3):139-147.

21. Perez JR, Smukler H, Nunn M. Clinical evaluation of the supraosseous gingivae before and after crown lengthening. J Periodontol 2007 Jun;78(6):1023-1030.

22. Gupta KK, Srivastava A, Singhal R, Srivastava S. An innovative cosmetic technique called lip repositiong. J Ind Soc Periodontol 2010 Oct;14(4):266-269. 